\title{
Mediators of Inflammation in Polycystic Ovary Syndrome in Relation to Adiposity
}

\author{
Thozhukat Sathyapalan and Stephen L. Atkin \\ Academic Endocrinology, Diabetes and Metabolism, Hull York Medical School, Michael White Diabetes Centre, \\ 220-236 Analby Road, Hull Royal Infirmary, Hull HU3 2JZ, UK \\ Correspondence should be addressed to Thozhukat Sathyapalan, thozhukat.sathyapalan@hyms.ac.uk
}

Received 27 October 2009; Accepted 18 March 2010

Academic Editor: Giuseppe Matarese

Copyright ( $\odot 2010$ T. Sathyapalan and S. L. Atkin. This is an open access article distributed under the Creative Commons Attribution License, which permits unrestricted use, distribution, and reproduction in any medium, provided the original work is properly cited.

Polycystic ovary syndrome (PCOS) is a common endocrine disorder in women of reproductive age group and is associated with a higher cardiovascular risk. Obesity, mainly visceral adiposity, is prevalent in patients with PCOS. Obesity is associated with lowgrade inflammation and raised inflammatory cytokines, both of which are also described in patients with PCOS. In this paper, the potential relationships between fat distribution, adipocyte dysfunction and, altered inflammatory markers in patients with PCOS have been discussed.

\section{Obesity in Polycystic Ovary Syndrome (PCOS)}

PCOS is one of the most common endocrine disorders in women of reproductive age with a prevalence of 5\%-7\% [13 ]. PCOS is associated with a broad range of adverse sequelae, including hypertension, dyslipidemia, insulin resistance, hyperandrogenaemia, gestational and type 2 diabetes, which ultimately increase the risk of cardiovascular morbidity [4-12]. Obesity is present in varying degrees in women with PCOS and is associated with hyperandrogenaemia and insulin resistance [13].

\section{Inflammatory Mediators in Obesity}

Obesity is associated with a state of chronic systemic inflammation manifested by increased serum levels of inflammatory cytokines as well as alterations in peripheral blood lymphocyte frequencies and function [14-16]. These changes are present not only at the tissue level but also in adipose, liver, and other tissue beds $[17,18]$. This inflammatory process could be the underlying cause of obesityrelated comorbidities, including atherosclerosis, diabetes and steatohepatosis [19-23].
Obesity-related inflammation is often considered a disorder of innate immunity. However, there is a significant crosstalk between innate and adaptive immune systems, and indeed disorders of both innate and adaptive immunity have been implicated in obesity-related inflammation [17, 24, 25].

Inflammation is not only an acute response to trauma or infection, it is also a response to the ongoing processes of cell turnover associated with aging [26]. In this regard, the inflammatory response regulates fundamental processes intrinsic to cellular homeostasis, including proliferation, necrosis, and apoptosis. In keeping with the task of regulating tissue turnover, inflammatory responses are triggered not only by exogenous stimuli, but also by endogenous stimuli, such as the by-products of cell necrosis and apoptosis. For example, free fatty acids, systemic levels of which are elevated in obesity, are primary ligands for Toll-like receptors, central regulators of the innate immune response $[27,28]$. Free fatty acids and Toll-like receptors therefore act as a direct link between the systems that regulate obesity and inflammation.

At the molecular level, the intracellular signalling pathways that govern inflammation and glucose homeostasis demonstrate significant crosstalk and share multiple signalling mediators. At the cellular level, adipocytes and macrophages are closely related and likely evolved from a 
common primordial precursor cell [29], further evidence of the parallel evolution of inflammation and metabolic systems.

\section{Inflammation and Insulin Resistance in Polycystic Ovary Syndrome}

Approximately $60 \%-70 \%$ of PCOS patients are obese [30], with a central body fat distribution pattern described as visceral obesity that is well known to be highly associated with insulin resistance. However, PCOS patients have evidence of insulin resistance independent of obesity [31-33]. Insulin sensitivity is decreased by $35 \%-40 \%$ in women with PCOS, independent of obesity, a decrease similar in magnitude to that seen in T2DM mellitus [34]; however, any degree of obesity further impairs insulin action. About $50 \%-70 \%$ of all women with PCOS have some degree of insulin resistance [35]. It is now evident that PCOS has major metabolic consequences related to insulin resistance. Insulin resistance is associated with an increased risk for several disorders, including type 2 diabetes, hypertension, dyslipidemia (low high-density lipoprotein cholesterol and high triglycerides), elevated plasminogen activator inhibitor type 1 (PAI-1), elevated endothelin-1, endothelial dysfunction, and heart disease.

Data have demonstrated a correlative as well as causative relationship between insulin resistance and inflammation [36]. Subclinical inflammation and insulin resistance are important predictors of cardiovascular disease [37]. Furthermore, in light of the role of insulin resistance in PCOS and of the increased cardiovascular risk of affected women, a relationship between inflammation and hormonal-metabolic features of women with PCOS has been demonstrated [38].

According to Rotterdam consensus criteria commonly used in clinical practice, two of the following three must be fulfilled for the diagnosis of PCOS: polycystic ovaries (12 or more follicles in each ovary, each follicle measuring 2-9 $\mathrm{mm}$ in diameter and/or ovarian volume $>10 \mathrm{~mL}$, one polycystic ovary is sufficient for the diagnosis), oligo-/anovulation; clinically diagnosed as oligo-/amenorrhea (menstrual cycles longer than 35 days or less than 10 menstruations per year) and hyperandrogenism (clinical or biochemical) [39]. In this consensus insulin resistance, metabolic syndrome, and obesity are not included in the diagnostic criteria to identify PCOS. However it is possible that some phenotypes of PCOS (i.e., those characterised by polycystic ovaries and oligomenorrhea as per Rotterdam consensus criteria) may simply reflect abnormal androgen and/or LH production without having metabolic implications.

It has been reported that women with PCOS have significantly increased hs-C-reactive protein (hs-CRP) concentrations [40], suggesting CRP a marker of low-grade inflammation, as a predictor of coronary heart disease and cardiovascular events in PCOS that is also independently related to insulin resistance. The leukocyte count was found to be significantly higher in women with PCOS compared with healthy women, although no case of leukocytosis was found in either group [38]. Regarding the leukocyte differential, significant increases in lymphocytes and monocytes were observed in women with PCOS compared with controls, which might have been expected considering that they play a key role in the pathophysiological mechanism of atherosclerosis [38]. Inflammation has been recognised to play a central role in both initiation and progression of the atherosclerotic process; therefore, an elevated leukocyte count should be directly associated with increased incidence of coronary heart disease, ischemic stroke, and mortality from cardiovascular disease [41].

In patients with PCOS circulating levels of tumour necrosis factor $\alpha$ (TNF $\alpha$ ), interleukin (IL)-6, hs-CRP, as well as white blood count (WBC) and neutrophil count have been found to be elevated compared with age- and /body mass index- (BMI-) matched controls [40, 42, 43]. In contrast, it has been shown that obesity, and not PCOS status per se, was a major determinants of the circulating inflammatory markers TNF $\alpha$, soluble type 2 TNF receptor, IL-6, and hs-CRP [44, 45]. Increase in both low-grade chronic inflammation and insulin resistance in women with PCOS is associated with increased central fat excess rather than PCOS status [46]. Furthermore, TNF $\alpha$ is over expressed in adipose tissue [47] and induces insulin resistance through acute and chronic effects on insulin-sensitive tissues. The source of excess circulating TNF $\alpha$ in PCOS is likely to be adipose tissue in the obese but remains unknown in lean women with the disorder. However, increased visceral obesity could be a source of excess TNF $\alpha$ in lean women with PCOS.

Another proinflammatory cytokine is IL-18, which was reported to be increased in PCOS [48]. IL-18 induces the production of TNF $\alpha$ which promotes the synthesis of IL-6, which is also considered a strong risk marker for cardiovascular disease [49]. Collectively, the above findings indicate that low-grade chronic inflammation could be a novel mechanism contributing to increased risk of coronary heart disease in PCOS.

Abdominal obesity is largely prevalent in obese women with PCOS [50]. Because of this, it is not surprising that the same alterations of abdominal obesity have been found in obese women with PCOS. In fact, compared with normal weight controls, obese women with PCOS present lower levels of adiponectin [51], increased levels of PAI-1 [52], increased activity of the angiotensin-renin system $[53,54]$, and increased cytokines and inflammatory markers [41]. However, obese patients with PCOS have more severe insulin resistance and higher androgen levels in comparison with non-PCOS women with abdominal obesity. Since both of these factors may affect adipocyte function, it is important to understand whether there are differences in production of adipose factors between obese women with PCOS and non-PCOS women with abdominal obesity. There were no differences in levels of leptin, resistin, and adiponectin between obese women with PCOS and obese controls [55]. There were also no differences in levels of TNF $\alpha$, IL- 6 , and markers of inflammation between obese women with PCOS and obese controls [41, 44]. A significant increase in PAI-1 levels between obese women with PCOS and obese controls has been reported [56]. However, comparing normal-weight patients with PCOS with controls of similar BMI, normoweight women with 
PCOS have higher serum levels of PAI-1, TNF $\alpha$ and lower adiponectin than normoweight controls [41, 53, 55]. All these data suggest that normoweight women with PCOS have an increased production of adipokines that is similar to that found in abdominal obesity. Since these patients present a mild hyperinsulinemia and insulin resistance [57], it is possible that it is sufficient to alter the adipocyte function. Consistent with this hypothesis, serum PAI-1 correlates with serum insulin in normoweight women with PCOS $[58,59]$. However, in the same group of patients, no correlation was found between serum adiponectin [55] or serum TNF $\alpha$ [41] and serum insulin levels or indices of insulin resistance. Even in overweight patients with PCOS no correlation between serum adiponectin and serum insulin or indices of insulin resistance was found [55].

Abundant leptin receptors have been detected in ovarian granulosa and theca cells [60]; furthermore, leptin treatment of these cells in vitro caused significant reduction in their steroid output [61]. It is possible that leptin has a dual effect on reproduction and that the major site of action differs according to the circulating levels [62]. Initial reports suggested that a substantial proportion of women with PCOS have leptin levels that are higher than expected for their BMI [63]. However subsequent studies have provided evidence that circulating leptin levels are fully accounted for by the degree of adiposity and BMI compared to matching control subjects [64-67]. On the other hand, it has also been reported that, for any given body weight, circulating leptin concentrations are lower in women with PCOS than those without, suggesting that neuroendocrine recognition of obesity may be impaired in such women [68].

Hyperinsulinemia alone is likely not sufficient to explain adipocyte dysfunction of normoweight women with PCOS. Theoretically, normoweight and overweight women with PCOS may have some degree of visceral obesity that is insufficient to effect an increase in body weight per se, but that may be sufficient to determine increased production of some adipokines [55]. On the other hand, visceral obesity and hyperinsulinemia are generally strictly related, and it is difficult to separate the two phenomena.

It has been shown that normoweight patients with PCOS have higher fat accumulation in visceral deposit [69] and lower subcutaneous fat in gluteofemoral area [70]. Although greater experiences and studies on the correlation between fat distribution and adipose products in normo-weight and overweight women with PCOS are needed, the available data suggest that in these patients, increased abdominal fat participates in the increased cardiovascular risk. Of course, insulin resistance is linked to the increase of visceral fat, and it may contribute to the adipocyte dysfunction of normoweight women with PCOS.

In conclusion, patients with PCOS present excessive fat accumulation in visceral deposits, and it plays an important role in their increased cardiovascular disease. This altered fat distribution is present not only in the obese, but also in normoweight patients with PCOS. Altered fat distribution and adipocyte dysfunction along with chronic lowgrade inflammation could be a novel mechanism contributing to increase in cardiovascular risk in PCOS.

\section{References}

[1] R. Azziz, K. S. Woods, R. Reyna, T. J. Key, E. S. Knochenhauer, and B. O. Yildiz, "The prevalence and features of the polycystic ovary syndrome in an unselected population," Journal of Clinical Endocrinology and Metabolism, vol. 89, no. 6, pp. 2745-2749, 2004.

[2] M. Asuncion, R. M. Calvo, J. L. San Millan, J. Sancho, S. Avila, and H. F. Escobar-Morreale, "A prospective study of the prevalence of the polycystic ovary syndrome in unselected Caucasian women from Spain," Journal of Clinical Endocrinology and Metabolism, vol. 85, no. 7, pp. 2434-2438, 2000.

[3] D. A. Ehrmann, "Polycystic ovary syndrome," The New England Journal of Medicine, vol. 352, no. 12, pp. 1223-1236, 2005.

[4] J. C. Lo, S. L. Feigenbaum, J. Yang, A. R. Pressman, J. V. Selby, and A. S. Go, "Epidemiology and adverse cardiovascular risk profile of diagnosed polycystic ovary syndrome," Journal of Clinical Endocrinology and Metabolism, vol. 91, no. 4, pp. 1357-1363, 2006.

[5] E. Dahlgren, P. O. Janson, S. Johansson, L. Lapidus, and A. Oden, "Polycystic ovary syndrome and risk for myocardial infarction: evaluated from a risk factor model based on a prospective population study of women," Acta Obstetricia et Gynecologica Scandinavica, vol. 71, no. 8, pp. 599-604, 1992.

[6] E. Dahlgren, S. Johansson, G. Lindstedt, et al., "Women with polycystic ovary syndrome wedge resected in 1956 to 1965: a long-term follow-up focusing on natural history and circulating hormones," Fertility and Sterility, vol. 57, no. 3, pp. 505-513, 1992.

[7] H.-Y. Son, A. Nishikawa, T. Ikeda, T. Imazawa, S. Kimura, and M. Hirose, "Lack of effect of soy isoflavone on thyroid hyperplasia in rats receiving an iodine-deficient diet," Japanese Journal of Cancer Research, vol. 92, no. 2, pp. 103-108, 2001.

[8] T. Pierpoint, P. M. McKeigue, A. J. Isaacs, S. H. Wild, and H. S. Jacobs, "Mortality of women with polycystic ovary syndrome at long-term follow-up," Journal of Clinical Epidemiology, vol. 51, no. 7, pp. 581-586, 1998.

[9] S. Wild, T. Pierpoint, H. Jacobs, and P. McKeigue, "Long-term consequences of polycystic ovary syndrome: results of a 31 year follow-up study," Human Fertility, vol. 3, no. 2, pp. 101$105,2000$.

[10] E. O. Talbott, D. S. Guzick, K. Sutton-Tyrrell, et al., "Evidence for association between polycystic ovary syndrome and premature carotid atherosclerosis in middle-aged women," Arteriosclerosis, Thrombosis, and Vascular Biology, vol. 20, no. 11, pp. 2414-2421, 2000.

[11] A. Vryonidou, A. Papatheodorou, A. Tavridou, et al., "Association of hyperandrogenemic and metabolic phenotype with carotid intima-media thickness in young women with polycystic ovary syndrome," Journal of Clinical Endocrinology and Metabolism, vol. 90, no. 5, pp. 2740-2746, 2005.

[12] R. C. Christian, D. A. Dumesic, T. Behrenbeck, A. L. Oberg, P. F. Sheedy II, and L. A. Fitzpatrick, "Prevalence and predictors of coronary artery calcification in women with polycystic ovary syndrome," Journal of Clinical Endocrinology and Metabolism, vol. 88, no. 6, pp. 2562-2568, 2003.

[13] T. M. Barber, M. I. McCarthy, J. A. H. Wass, and S. Franks, "Obesity and polycystic ovary syndrome," Clinical Endocrinology, vol. 65, no. 2, pp. 137-145, 2006.

[14] J.-P. Bastard, C. Jardel, E. Bruckert, et al., "Elevated levels of interleukin 6 are reduced in serum and subcutaneous adipose tissue of obese women after weight loss," Journal of Clinical 
Endocrinology and Metabolism, vol. 85, no. 9, pp. 3338-3342, 2000.

[15] R. W. O’Rourke, T. Kay, E. A. Lyle, et al., "Alterations in peripheral blood lymphocyte cytokine expression in obesity," Clinical and Experimental Immunology, vol. 146, no. 1, pp. 39 46, 2006.

[16] A. Festa, R. D’Agostino Jr., K. Williams, et al., "The relation of body fat mass and distribution to markers of chronic inflammation," International Journal of Obesity, vol. 25, no. 10, pp. 1407-1415, 2001.

[17] R. Cancello, J. Tordjman, C. Poitou, et al., "Increased infiltration of macrophages in omental adipose tissue is associated with marked hepatic lesions in morbid human obesity," Diabetes, vol. 55, no. 6, pp. 1554-1561, 2006.

[18] K. Clement, N. Viguerie, C. Poitou, et al., "Weight loss regulates inflammation-related genes in white adipose tissue of obese subjects," FASEB Journal, vol. 18, no. 14, pp. 16571669, 2004.

[19] M. A. E. A. Diehl, "Nonalcoholic steatosis and steatohepatitis IV. Nonalcoholic fatty liver disease abnormalities in macrophage function and cytokines," American Journal of Physiology, vol. 282, no. 1, pp. G1-G5, 2002.

[20] M. C. Arkan, A. L. Hevener, F. R. Greten, et al., "IKK- $\beta$ links inflammation to obesity-induced insulin resistance," Nature Medicine, vol. 11, no. 2, pp. 191-198, 2005.

[21] U. Schonbeck, F. Mach, G. K. Sukhova, et al., "CD40 ligation induces tissue factor expression in human vascular smooth muscle cells," American Journal of Pathology, vol. 156, no. 1, pp. 7-14, 2000.

[22] C. A. Reardon and G. S. Getz, "Mouse models of atherosclerosis," Current Opinion in Lipidology, vol. 12, no. 2, pp. 167-173, 2001.

[23] K. S. Michelsen, M. H. Wong, P. K. Shah, et al., "Lack of Tolllike receptor 4 or myeloid differentiation factor 88 reduces atherosclerosis and alters plaque phenotype in mice deficient in apolipoprotein E," Proceedings of the National Academy of Sciences of the United States of America, vol. 101, no. 29, pp. 10679-10684, 2004.

[24] H. Wu, S. Ghosh, X. D. Perrard, et al., "T-cell accumulation and regulated on activation, normal $\mathrm{T}$ cell expressed and secreted upregulation in adipose tissue in obesity," Circulation, vol. 115, no. 8, pp. 1029-1038, 2007.

[25] U. Kintscher, M. Hartge, K. Hess, et al., "T-lymphocyte infiltration in visceral adipose tissue: a primary event in adipose tissue inflammation and the development of obesitymediated insulin resistance," Arteriosclerosis, Thrombosis, and Vascular Biology, vol. 28, pp. 1304-1310, 2008.

[26] F. Licastro, G. Candore, D. Lio, et al., "Innate immunity and inflammation in ageing: a key for understanding age-related diseases," Immunity and Ageing, vol. 2, article 8, 2005.

[27] J. E. Davis, N. K. Gabler, J. Walker-Daniels, and M. E. Spurlock, "Tlr-4 deficiency selectively protects against obesity induced by diets high in saturated fat," Obesity, vol. 16, no. 6, pp. 1248-1255, 2008.

[28] A. Schaeffler, P. Gross, R. Buettner, et al., "Fatty acid-induced induction of Toll-like receptor-4/nuclear factor- $\kappa \mathrm{B}$ pathway in adipocytes links nutritional signalling with innate immunity," Immunology, vol. 126, no. 2, pp. 233-245, 2009.

[29] G. Charriere, B. Cousin, E. Arnaud, et al., "Preadipocyte conversion to macrophage: evidence of plasticity," Journal of Biological Chemistry, vol. 278, no. 11, pp. 9850-9855, 2003.

[30] D. A. Ehrmann, R. B. Barnes, R. L. Rosenfield, M. K. Cavaghan, and J. Imperial, "Prevalence of impaired glucose tolerance and diabetes in women with polycystic ovary syndrome," Diabetes Care, vol. 22, no. 1, pp. 141-146, 1999.

[31] A. Dunaif, K. R. Segal, W. Futterweit, and A. Dobrjansky, "Profound peripheral insulin resistance, independent of obesity, in polycystic ovary syndrome," Diabetes, vol. 38, no. 9, pp. 11651174, 1989.

[32] R. J. Chang, R. M. Nakamura, H. L. Judd, and S. A. Kaplan, "Insulin resistance in nonobese patients with polycystic ovarian disease," Journal of Clinical Endocrinology and Metabolism, vol. 57, no. 2, pp. 356-359, 1983.

[33] T. P. Ciaraldi, A. El-Roeiy, Z. Madar, D. Reichart, J. M. Olefsky, and S. S. C. Yen, "Cellular mechanisms of insulin resistance in polycystic ovarian syndrome," Journal of Clinical Endocrinology and Metabolism, vol. 75, no. 2, pp. 577-583, 1992.

[34] J. B. O’Driscoll, H. Mamtora, J. Higginson, A. Pollock, J. Kane, and D. C. Anderson, "A prospective study of the prevalence of clear-cut endocrine disorders and polycystic ovaries in 350 patients presenting with hirsutism or androgenic alopecia," Clinical Endocrinology, vol. 41, no. 2, pp. 231-236, 1994.

[35] R. S. Legro, V. D. Castracane, and R. P. Kauffman, "Detecting insulin resistance in polycystic ovary syndrome: purposes and pitfalls," Obstetrical and Gynecological Survey, vol. 59, no. 2, pp. 141-154, 2004.

[36] Z. T. Bloomgarden, "Inflammation and insulin resistance," Diabetes Care, vol. 26, no. 6, pp. 1922-1926, 2003.

[37] W. H. Frishman, "Biologic markers as predictors of cardiovascular disease," American Journal of Medicine, vol. 104, no. 6, pp. 18S-27S, 1998.

[38] F. Orio Jr., S. Palomba, T. Cascella, et al., "The increase of leukocytes as a new putative marker of low-grade chronic inflammation and early cardiovascular risk in polycystic ovary syndrome," Journal of Clinical Endocrinology and Metabolism, vol. 90, no. 1, pp. 2-5, 2005.

[39] The Rotterdam ESHRE/ASRM-Sponsored PCOS Consensus Workshop Group, "Revised 2003 consensus on diagnostic criteria and long-term health risks related to polycystic ovary syndrome," Human Reproduction, vol. 19, no. 1, pp. 41-47, 2004.

[40] C. C. J. Kelly, H. Lyall, J. R. Petrie, G. W. Gould, J. M. C. Connell, and N. Sattar, "Low grade chronic inflammation in women with polycystic ovarian syndrome," Journal of Clinical Endocrinology and Metabolism, vol. 86, no. 6, pp. 2453-2455, 2001.

[41] F. Gonzalez, K. Thusu, E. Abdel-Rahman, A. Prabhala, M. Tomani, and P. Dandona, "Elevated serum levels of tumor necrosis factor alpha in normal-weight women with polycystic ovary syndrome," Metabolism, vol. 48, no. 4, pp. 437-441, 1999.

[42] R. W. Alexander, "Inflammation and coronary artery disease," The New England Journal of Medicine, vol. 331, no. 7, pp. 468469, 1994.

[43] G. Amato, M. Conte, G. Mazziotti, et al., "Serum and follicular fluid cytokines in polycystic ovary syndrome during stimulated cycles," Obstetrics and Gynecology, vol. 101, no. 6, pp. 1177-1182, 2003.

[44] H. F. Escobar-Morreale, G. Villuendas, J. I. Botella-Carretero, J. Sancho, and J. L. San Millan, "Obesity, and not insulin resistance, is the major determinant of serum inflammatory cardiovascular risk markers in pre-menopausal women," Diabetologia, vol. 46, no. 5, pp. 625-633, 2003.

[45] M. Mohlig, J. Spranger, M. Osterhoff, et al., "The polycystic ovary syndrome per se is not associated with increased chronic 
inflammation," European Journal of Endocrinology, vol. 150, no. 4, pp. 525-532, 2004.

[46] J. J. Puder, S. Varga, M. Kraenzlin, C. De Geyter, U. Keller, and B. Muller, "Central fat excess in polycystic ovary syndrome: relation to low-grade inflammation and insulin resistance," Journal of Clinical Endocrinology and Metabolism, vol. 90, no. 11, pp. 6014-6021, 2005.

[47] G. S. Hotamisligil, N. S. Shargill, and B. M. Spiegelman, "Adipose expression of tumor necrosis factor- $\alpha$ : direct role in obesity-linked insulin resistance," Science, vol. 259, no. 5091, pp. 87-91, 1993.

[48] J. M. Stephens, M. D. Butts, and P. H. Pekala, "Regulation of transcription factor mRNA accumulation during 3T3-L1 preadipocyte differentiation by tumour necrosis factor- $\alpha$," Journal of Molecular Endocrinology, vol. 9, no. 1, pp. 61-72, 1992.

[49] S. Blankenberg, L. Tiret, C. Bickel, et al., "Interleukin-18 is a strong predictor of cardiovascular death in stable and unstable angina," Circulation, vol. 106, no. 1, pp. 24-30, 2002.

[50] J. Bringer, P. Lefebvre, F. Boulet, et al., "Body composition and regional fat distribution in polycystic ovarian syndrome: relationship to hormonal and metabolic profiles," Annals of the New York Academy of Sciences, vol. 687, pp. 115-123, 1993.

[51] D. Panidis, A. Kourtis, D. Farmakiotis, T. Mouselech, D. Rousso, and G. Koliakos, "Serum adiponectin levels in women with polycystic ovary syndrome," Human Reproduction, vol. 18, no. 9, pp. 1790-1796, 2003.

[52] C. J. G. Kelly, H. Lyall, J. R. Petrie, et al., "A specific elevation in tissue plasminogen activator antigen in women with polycystic ovarian syndrome," Journal of Clinical Endocrinology and Metabolism, vol. 87, no. 7, pp. 3287-3290, 2002.

[53] T.-A. Jaatinen, I. Matinlauri, L. Anttila, P. Koskinen, R. Erkkola, and K. Irjala, "Serum total renin is elevated in women with polycystic ovarian syndrome," Fertility and Sterility, vol. 63, no. 5, pp. 1000-1004, 1995.

[54] R. S. Morris, I. L. Wong, I. E. Hatch, E. Gentschein, R. J. Paulson, and R. A. Lobo, "Prorenin is elevated in polycystic ovary syndrome and may reflect hyperandrogenism," Fertility and Sterility, vol. 64, no. 6, pp. 1099-1103, 1995.

[55] E. Carmina, F. Orio, S. Palomba, et al., "Evidence for altered adipocyte function in polycystic ovary syndrome," European Journal of Endocrinology, vol. 152, no. 3, pp. 389-394, 2005.

[56] F. Orio Jr., S. Palomba, T. Cascella, et al., "Is plasminogen activator inhibitor-1 a cardiovascular risk factor in young women with polycystic ovary syndrome?" Reproductive BioMedicine Online, vol. 9, no. 5, pp. 505-510, 2004.

[57] A. Dunaif, "Insulin resistance and the polycystic ovary syndrome: mechanism and implications for pathogenesis," Endocrine Reviews, vol. 18, no. 6, pp. 774-800, 1997.

[58] M. Sampson, C. Kong, A. Patel, R. Unwin, and H. S. Jacobs, "Ambulatory blood pressure profiles and plasminogen activator inhibitor (PAI-1) activity in lean women with and without the polycystic ovary syndrome," Clinical Endocrinology, vol. 45, no. 5, pp. 623-629, 1996.

[59] E. S. Sills, C. D. Drews, M. Perloe, M. J. Tucker, C. R. Kaplan, and G. D. Palermo, "Absence of profound hyperinsulinism in polycystic ovary syndrome is associated with subtle elevations in the plasminogen activator inhibitor system," Gynecological Endocrinology, vol. 17, no. 3, pp. 231-237, 2003.

[60] C. Karlsson, K. Lindell, E. Svensson, et al., "Expression of functional leptin receptors in the human ovary," Journal of Clinical Endocrinology and Metabolism, vol. 82, no. 12, pp. 4144-4148, 1997.
[61] L. J. Spicer and C. C. Francisco, "The adipose obese gene product, leptin: evidence of a direct inhibitory role in ovarian function," Endocrinology, vol. 138, no. 8, pp. 3374-3379, 1997.

[62] M. Caprio, E. Fabbrini, A. M. Isidori, A. Aversa, and A. Fabbri, "Leptin in reproduction," Trends in Endocrinology and Metabolism, vol. 12, no. 2, pp. 65-72, 2001.

[63] P. R. Brzechffa, A. J. Jakimiuk, S. K. Agarwal, S. R. Weitsman, R. P. Buyalos, and D. A. Magoffin, "Serum immunoreactive leptin concentrations in women with polycystic ovary syndrome," Journal of Clinical Endocrinology and Metabolism, vol. 81, no. 11, pp. 4166-4169, 1996.

[64] I. M. Chapman, G. A. Wittert, and R. J. Norman, "Circulating leptin concentrations in polycystic ovary syndrome: relation to anthropometric and metabolic parameters," Clinical Endocrinology, vol. 46, no. 2, pp. 175-181, 1997.

[65] J. Rouru, L. Anttila, P. Koskinen, et al., "Serum leptin concentrations in women with polycystic ovary syndrome," Journal of Clinical Endocrinology and Metabolism, vol. 82, no. 6, pp. 1697-1700, 1997.

[66] C. S. Mantzoros, S. Moschos, I. Avramopoulos, et al., "Leptin concentrations in relation to body mass index and the tumor necrosis factor- $\alpha$ system in humans," Journal of Clinical Endocrinology and Metabolism, vol. 82, no. 10, pp. 3408-3413, 1997.

[67] M. H. Telli, M. Yildirim, and V. Noyan, "Serum leptin levels in patients with polycystic ovary syndrome," Fertility and Sterility, vol. 77, no. 5, pp. 932-935, 2002.

[68] G. S. Conway and H. S. Jacobs, "Leptin: a hormone of reproduction," Human Reproduction, vol. 12, no. 4, pp. 633635, 1997.

[69] S. Kirchengast and J. Huber, "Body composition characteristics and body fat distribution in lean women with polycystic ovary syndrome," Human Reproduction, vol. 16, no. 6, pp. 1255-1260, 2001.

[70] R. Horejsi, R. Moller, S. Rackl, et al., "Android subcutaneous adipose tissue topography in lean and obese women suffering from PCOS: comparison with type 2 diabetic women," American Journal of Physical Anthropology, vol. 124, no. 3, pp. 275-281, 2004. 


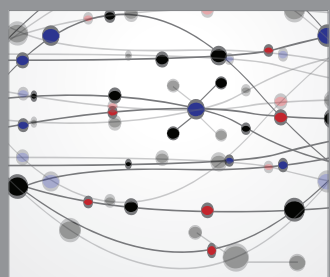

The Scientific World Journal
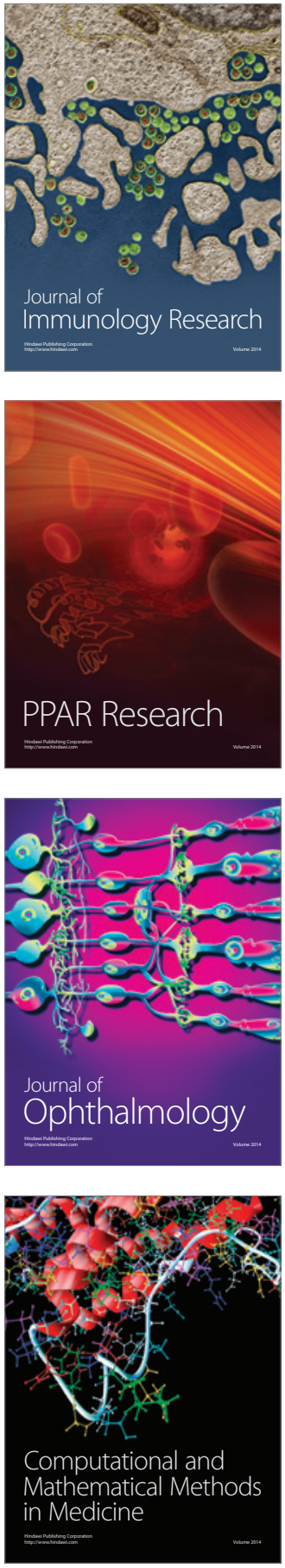

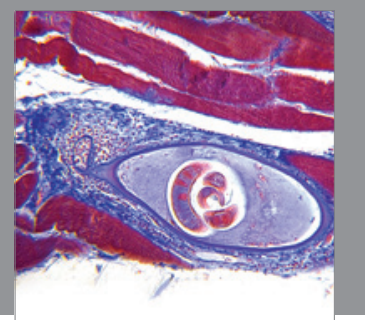

Gastroenterology

Research and Practice
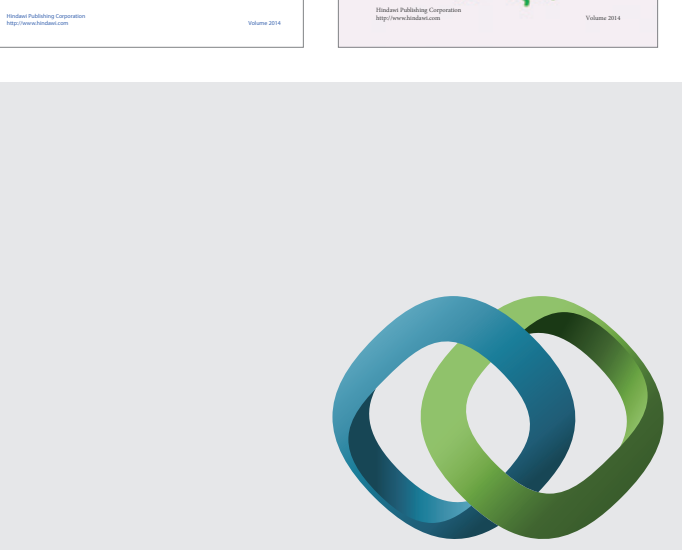

\section{Hindawi}

Submit your manuscripts at

http://www.hindawi.com
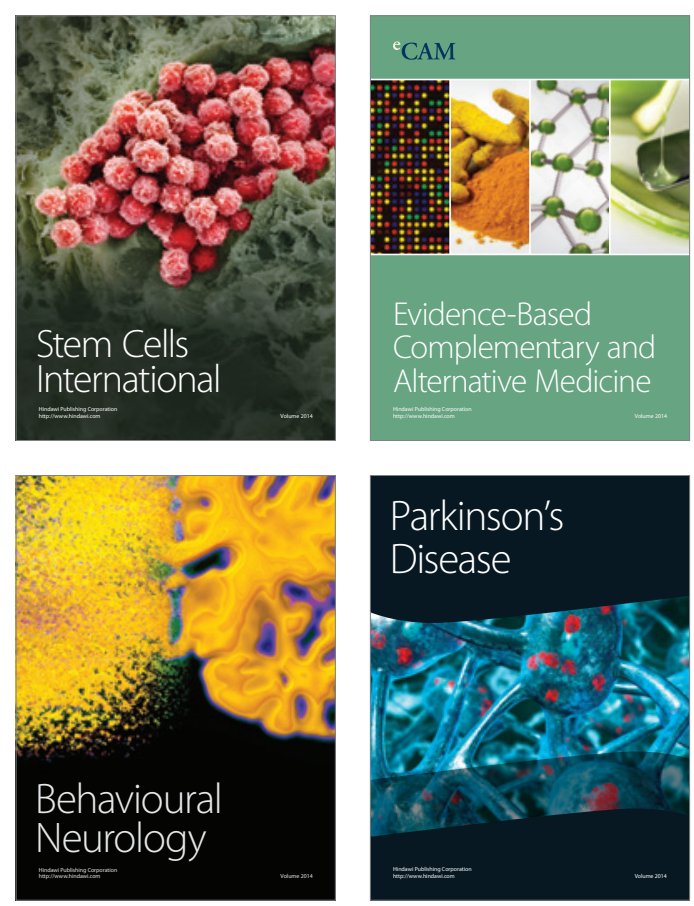

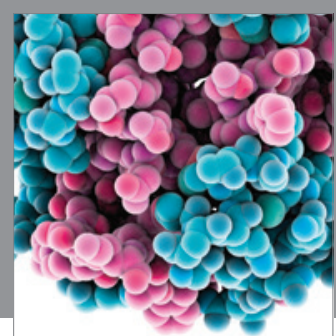

Journal of
Diabetes Research

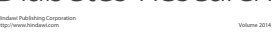

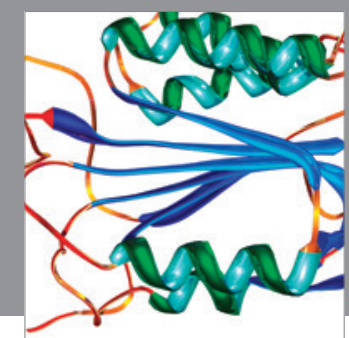

Disease Markers
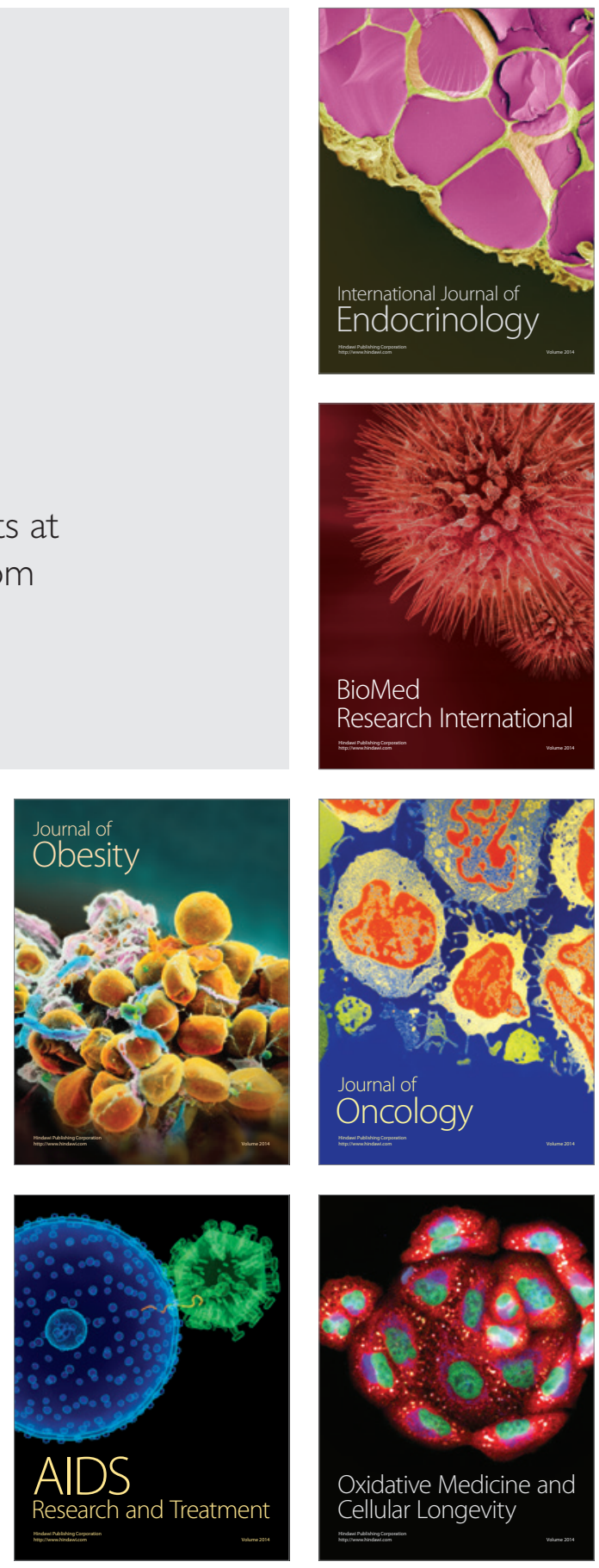